training in a biologic laboratory, for this furnishes the student of anatomy and physiology with such skill as will enable him at once to get the most that is possible out of these subjects as they are taught in the best university medical schools. A knowledge of comparative anatomy will make human anatomy easier and more interesting. It is not, however, as essential for the beginner in medicine as the subjects just mentioned. For the graduate, French and German are essential, in order to keep abreast of professional progress; therefore, they should be acquired preparatory to medicine. Botany, psychology and logic, like comparative anatomy, make the acquirement of other medical subjects easier and increase the pleasure and interest of the student in them.

If four of the most important of these subjects are added to existing entrance requirements, they will rarely be acquired by students in less than two years in colleges of arts or sciences, for, although in themselves they do not make more than a year's work, the schedules of colleges are so planned that they can not be taken simultaneously; and if all the subjects named were required, a college residence of at least three years would be needed. Almost without exception, therefore, other and less technical subjects will be studied as well.

A change in the entrance requirements of medical colleges which is needed, and which will do more to improve the quality of the student body than almost anything else, is to stop admitting on certificates, and to require of all who enter thorough examinations in a few required subjects.

The ideal course for medical students is a combined one of six years, leading to both the degrees of B.S. or A.B. and M.D., which such universities as Michigan, Northwestern and Chicago have been offering. Three years are spent in Michigan and Northwestern in the college of arts, during which time almost or quite all of the freshman course in medicine is completed. Three years more are spent in the medical school. At Chicago Unirersity two years are spent in the arts department and four in the medical. Harvard and Cornell make a seven-year combined course. It is so usual for all the best graduates in medicine to spend eighteen months or two years in post-graduate work that these combined courses should be made no longer than is absolutely necessary, for it is as much a detriment to the beginning practitioner to be too old as to be too young. A combined course should be completed, if possible, when the student is 24 or 25 years old. For many years a longer period of education has been required of students of medicine than for those preparing for other professions, although the emoluments of practitioners are no greater, nor as great, as those which the practice of law makes possible. Therefore, neither proparation for the study of medicine nor the arrangement of subjects in the medical curriculum should be allowed to too greatly prolong the student's period of academic and college work.

Method of Arresting Epistaxis.-Matthews is quoted by the Journal Mćd. de Paris as advocating a condom for arresting hemorrhage from the nose. (This has been mentioned before.) The condom is oiled and inserted in the nose on the end of a eatheter. The latter is then partly withdrawn, and through it the condom is inflated. The outer end is then tied around the eatheter, and thus forms a "balloon tampon," which can be easily removed at any time without disturbing the clots, by allowing the air to escape first.

\section{CO-OPERATIVE METHODS FOR IMPROVING \\ THE USEFULNESS OF STATISTICAL CLASSIFICATIONS OF CAUSES OF DEATH.*}

CRESSY L. WILBUR, M.D.

Chief of Division of Vital Statistics, Department of State, Michigan, and Medical Referee of the United States Census

in Vital Statistics.

LANSING, MICH.

One of the most important matters involved in the administration of a registration office is the selection and proper use of a statistical classification of causes of death. The mortality from various diseases must be known in order that the value of methods adopted by sanitary officers for their prevention and restriction may be appreciated, and it is important for many reasons that accurate and fully comparable statistics of causes of death be published. 'This presupposes the use of some classification of causes of death.

It may be said that the use of a formal classification is unnecessary, as the causes returned by physicians might be stated in alphabetical order. This would be possible for only the smallest areas of registration, and for short periods of time. For a large city, a state, or for the country as a whole, the number of different terms returned as causes of death would be so numerous that it would not be feasible to give each one a separate line in statistical tables. Even where it has been attempted to make use of the alphabetical arrangement numerous terms have usually been condensed under single titles, so that a method of classification was actually in use. Where this is not the case the statistics may be very misleading, and may give rise to annoying blunders on the part of those consulting them unless they first complete the work of proper statistical compilation that was left unfinished by the registration office. As an amusing instance, I may quote the following from a recent issue of The Jodrnal of the American Medical Association, wnder the heading, "Clippings From Lay Exchanges":

Tuberculosis of the lungs carried off twenty-five of the victims of disease last month. Seven others died of tuberculosis and four of phthisis.

It may be well at this point. to call attention to the limited sense in which the word "classification" is now employed in this connection. It does not refer to a broad and comprehensive philosophical arrangement of diseases, based on general principles and intended to show the natural or scientific relations of the diseases or causes of death. If this were the object of a statistical classification of causes of death at the present time, it would be necessary to acknowledge failure from the start. No ideal classification fully exhibiting the natural relations of diseases and meeting the demands of all classes of scientific workers is yet possible. The tendency is strongly in the direction of doing away with all $80^{-}$ called "groups" or "classes" of diseases and of placing stress chiefly on the definite meaning and inclusion of the individual titles. "Classification," said Dr. Farr, "is another name for generalization." Our object at the present time in statistical classification of causes of death is to do away with generalization as far as possible. The old statistical groups of "zymotic diseases," "constitutional diseases," "diathetic diseases," and the like, have disappeared, or remain only as belated relics of a former nomenclature. Even the distinction between "general

- Read at the Fifty-fourth Annual Session of the American Medical $\Delta$ ssociation, in the Section on Hyglene and Samites: Science, and approved for publication by the Execut Drs. S. Fulton, Beneca Egbert and H. M. Bracken. 
diseases" and "local diseases" can not be considered of any special importance to-day. The boundary is elastic, and a so-called "local" disease of to-day is placed by the advanced pathology of to-morrow among the general infections.

By the adoption of a statistical classification of causes of death, therefore, we mean nothing more than the use of a certain number of titles of diseases, each with a definite inclusion of terms as returned by physicians on certificates of death. For convenience a certain general arrangement is usually followed, as in the International Classification, now in general use in this country. The titles of this system and the detailed list of terms included under each title are given in the Manual of the International Classification, published last year by the United States Census Office.

This classification was reported by Dr. Jacques Bertillon, as chairman of a committee of the International Statistical Institute at the session held in Chicago in 1893. It was the result of a movement for uniformity in statistics of causes of death that had engaged the attention of registration officials and users of mortality statistics for half a century. The Conference of State and Provincial Boards of Health indorsed it at Detroit in 1897, and the American Public Health Association recommended its general use at Ottawa in 1898, and reported a plan for its regular decennial revision by an international commission to meet at Paris in 1900. This recommendation was indorsed by the International Statistical Institute at Christiania in 1899 , and the international commission for the first revision of the classification met at Paris, August 18-21, 1900, by invitation of the French government, representatives from twentysix countries taking part in the sessions. This Section of the American Medical Association adopted a resolution in its favor at Atlantic City in 1900, and it has since been accepted by every registration state, most of the leading cities, the United States Census Office, United States Department of Labor, etc. It has been adopted by Canada, Mexico and by the countries of Central and South America, and has no rival as an international classification.

Its imperfections have never been ignored by the strongest advocates of its general adoption. It is faulty, as are all other systems. The reason for its use lies not in any perfection of the system, but because it was possible by adopting it to unite on a general basis of uniformity. This we have done, and we are now ready, by coöperative work, to amend and improve it, and make it, by means of the periodical revisions that all classifications require, more definite, more practical, more useful in every sense of the term to all who have occasion to employ statistics of causes of death.

How shall this be done? Only by enlisting the aid of all users of mortality statistics, and ascertaining in just what respects the system requires alteration to best serve their wishes.

Here it may be necessary to explain in fuller detail just what are the relations of vital statisticians to the matter of classification of causes of death generally.

is the source of information in regard to causes of death is the medical profession. The individual physician who makes a statement on the medical certifieate of cause practich in regard to a case that has occurred in his practice makes the first contribution to that mass of data cate which come the mortality statistics. The certifition signed by the physician goes into the local registrait office and is there recorded. Possibly, if in a city, it may be compiled there, and the mortality statistics accompanying the annual report of the city board of health be derived therefrom. In our state, as in some other registration states, the certificate is next sent to the central registration office at the capital, and is there permanently preserved. It is again compiled,first, for the Monthly Bulletin of Vital Statistics, and, second, after all delayed returns and corrections have been received, for the annual registration report. Lastly, a transcript of this certificate goes to the United States Census Office at Washington, where it is not recorded, but where the information is transferred to the cards employed in the electric tabulating machinery, and it is again compiledthis time for the annual report on mortality now required by law to be prepared by the permanent Census Office. This is the final statistical report, but all alike-the national, state and local compilations-agree in the fact that the original certificate of death signed by the attending physician is the source of all information. The validity of the statistics can not rise above the authority of their source, and, if the original statements of causes of death as made by the physicians are vague, indefinite and full of error, then the statistics must be defective and unsatisfactory to precisely the same degree.

Compilation is that process by which statistics are derived from the mass of individual records, and, for our special purpose, may be limited to the production of the finished tables of causes of death showing their various relations by locality, date of occurrence, age, sex, color, nativity, etc. It should be a colorless medium by which all of the important features of the original returns may be preserved, in condensed form, and nothing should be added to or subtracted from the significance of the original statements.

Here we may note two leading difficulties of compilation. These are, first, the condensation of the extensive list of terms reported by physicians to fit the comparatively short list of titles alone feasible in statistical reports, and second, the selection of the proper title for compilation when two or more causes have been assigned by the physician. These difficulties increase with the mass of returns to be handled, and are more pressing in the larger offices, where the vast mass of causes and complications renders some uniform system of procedure indispensably necessary.

Some idea of the large number of causes reported by physicians may be gained from examination of the Census Manual of the International Classification. Each one of these terms, with the exception of a few translated from the report of the French commission, has been actually returned on a certificate of death by some physician in the United States. And, moreover, any two or three of these terms may occur on a single certificate, and in any combination. If there were only 5,000 different terms, and there are many more than that, then there would be $25,000,000$ different binary combinations of those terms possible, or, disregarding the order of the terms, which is seldom important, there would be 12,500,000 combinations of different terms. Practically, such combinations are endless in variety, and yet in the process of compilation all of these 5,000 terms and 12,500,000 possible combinations must be reduced to the exact number of titles in the system selected. In the International Classification there are only 179 titles in the detailed form, and no classification much exceeds this number.

This process of condensation of medical terms under synonymous titles, or the selection of the true cause of death from several causes assigned by the physician, constitutes a large part of the practical work of a regis- 
tration office in the treatment of causes of death. To be of value it must be under medical supervision, and yet, from the considerable amount of clerical labor involved, it is rare to find that a qualified medical statistician passes on each individual certificate of death. As a rule, certain principles and methods of procedure are established, and only exceptional cases are referred to expert judgment. Even if competent medical statisticians gave their personal attention to the assignment of each certificate of death compiled in the various offices, there would be numerous differences of practice, and consequent variations in the resulting statistics, unless a comprehensive system of treatment were adopted in all alike.

The adoption of such a system of assignment of individual single terms is the characteristic feature of the International Classification, which renders it superior for general adoption and the promotion of uniformity to any other system now in use. It gives the title to which each individual term is to be assigned. The question of assignment to one title or another, or the formation of new titles, is a proper subject for settlement at the regular decennial revisions, but between the revisions each term has a definite place in the classification, and all offices using the classification put it there. For the use of other systems there is no authoritative guide. A registration office in this country that undertook to employ the English registrar-general's classification might do so, so far as outward form was concerned, but there would be no assurance that the terms received from physicians' certificates were assigned as the registrargeneral would assign them. Each office would be a law unto itself, just as in the old days before the adoption of uniform methods under the international classification.

For the treatment of jointly-returned causes of death no systematic method applicable to all classes of returns has as yet been introduced. It is usual in statistical offices to keep a book of practice showing decisions in such cases, and in time precedents may be collected showing the assignments of the most common causes when returned together. Attention was called to the importance of the subject by Würzburger at the session of the International Commission at Paris, and a tabular arrangement showing the preferences to be given individual titles of the classification was appended to the report of the Commission by Dr. Bertillon. This method, however, deals only with the definite titles, not with the numerous terms of varying degrees of accuracy included under the titles, and the judgment of the statistician would often be required as to whether the relative assignments of certain titles should govern the assignments of certain terms included. Many cases, moreover, including some of the most difficult, and practically all of the terms embraced under general or residual titles, are left to unguided individual decision.

Consideration of the difficulties attending this class of decisions and analysis of the process by which a final judgment was usually arrived at have suggested another plan for the systematic treatment of jointly-returned causes, and one which, in addition, seems adapted to the thorough revision of the international classification so that it will most fully meet the wishes of all of its users. This plan is set forth in a circular ${ }^{1}$ of the Committee of

1. The circular was presented in connection with this paper, together with some preliminary ratings of titles of the International Classiflcation obtained under it which sbowed the usefulness and circular, the special blank, with instructions, prepared for rating the titles of the classification and other information inquiry should be addressed to Mr. W. A. King, Chler Statisticlan of the U. S. Census, Washington. D. C., who is chairman of the American Public Health Association's committee. the American Public Health Association on Demography and Statistics in Their Sanitary Relations.

When a death is returned from two causes, e. g., typhoid fever and valvular disease of the heart, one of these terms must be selected. The death can not be compiled under both typhoid fever and organic heart disease-at least it can not in any present system of classification. Which shall be chosen? Which title will best represent this case in the compiled statistical tables? Which will best serve the purposes of the users of the statistics?

When the terms, as in the example above, are exactly the same as, or fully equivalent to, the titles of the classification, then the question resolves itself into: "Which title is more important?" Different answers may be given to such a question. The sanitarian, regarding typhoid fever as a dangerous communicable disease, and interested in its prevention, wants to know the exact number of deaths from this disease. He cares nothing about organic heart disease, relatively, but says at once: "Put it under typhoid fever." The actuary or medical director of a life insurance company, dealing with such a return, might consider the statement of heart disease the more important. As a matter of fact, the individual might not have succumbed from typhoid fever if the heart had not been affected, and might have lived for many years with the heart affection but for the intercurrent attack of typhoid fever. The clinician, the pathologist, the sanitarian, the actuary each may have a different opinion. It is the duty of the vital statistician to endeavor to satisfy the wishes of all, as far as possible, and for that purpose it is necessary to ask for the opinion of each class of users of mortality statistics. Such opinions to be available for use must be comparable, and the most obvious way of attaining this object was to ask for numerical answers. "That would you rate the importance of each title on a definite scale, say from 0 to 10 ?" Then the more important title, as numerically rated for general purposes, should be preferred, no data as to relative duration, primary or secondary occurrence, etc., being available to modify such judgment.

In a similar case, suppose the return to have been "continued fever" and valvular heart disease. Now, "continued fever," stated alone, is compiled under typhoid fever, but there is some uncertainty about it. It can not be considered as fully equivalent to this title. The registrar in estimating its value as compared with the other cause assigned, necessarily considers this fact, and may decide that a doubtful statement of typhoid fever is less satisfactory for compilation than a positive one of organic heart disease. In other words, we consider two factors in deciding every case of independent joint causes, first, the relative importance of the titles to which the terms would be assigned, and second, the validity of the terms as more or less certainly belonging under the titles selected.

Both of these factors are capable of numerical rating on the decimal or other scale. Having rated the importance of each title, and also the validity of each term as related to its title assigned, then the product of these numbers will give a general weighting number or com bining number for each term returned on a certificate of death, by means of which the preference to be gively in classification, i. e., assignment to titles, is definitely indicated. Provision would necessarily be made fuld equal rates, but a rery large proportion of cases would be decided directly by the combining numbers.

A very practical advantage of such a system is that the combining numbers or weights could be readily in- 
serted in an ordinary index of causes, as in that of the Census Manual, without increasing its length br a single page, and that the decisions between any two out of, say 5,000 terms, could be instantly found. Many millions of separate decisions would be thus condensed, which, expressed in any other way, would require many pages to record, and would be a vast, perhaps insuperable labor to frame. And the principle of each individual decision, as made between two independent terms coming before the registrar, would be precisely the same as that derived from his previously recorded numerical judgment, as expressed in a rating.

It is not my intention to urge that the classification of causes of death shall be an entirely mechanical process. To accomplish the best results it must necessarily be conducted under medical direction, and first-hand examination of the original certificates will often disclose valuable suggestions as to the true place of the return in classification. Nevertheless, the most accomplished medical statistician will find cases where his judgment is uncertain, or where, at different times, he may make contrary decisions. A series of rating numbers would then be most useful, and would tend to unify practice. For many offices, however, where the compilation of data is left more or less entirely to clerks who do not possess medical qualifications, the plain and explicit directions available by means of the ratings would be invaluable.

The advantages of such a system for the criticism and revision of the classification are obvious. With each title and each constituent term assigned a definite value in the opinions of the chief users of statistics, it would be merely necessary to lop off titles of little consequence, and to exclude terms of very uncertain validity under the titles to greatly improve the precision and usefulness of the system. In some cases titles of slight precision would have to be retained on account of the large number of returns received under them, but their low value would be forcibly called to attention, and, in time, the physicians might be brought to avoid them. Indefinite terms that now vitiate the statistics of certain causes would be thrown out by this process of sifting, and a thoroughly revised and renovated classification would be the result. It is physically impossible for a commission to consider all of the points that require attention in an ordinary session of a few days, but with the concrete opinion of registrars, clinicians, pathologists, sanitarians and other classes of users of mortality statistics, definitely expressed in advance and capable of numerical analysis, the work of revision should be most complete and satisfactory.

At present all classifications are lumbered to some extent with useless titles. These are titles of little precision, of rare occurrence, or divided more minutely than the accuracy of returns will warrant. On the other
hand, some diseases of great importance are lumped together without reference to the very important clinical, pathologic and etiologic distinctions that should be observed. It might be possible, by eliminating titles of
small death consequence, to obtain statistics of the causes of and of first importance, in all their necessary details, and also to add a selected list of the most important limitinations of causes, without exceeding the usual imit of registration reports.

What is needed at the present time is a full expression tistical pron on the practical matters relating to the stamedical presentation of causes of death from the entire begun the task, because the collection and publication of vital statistics is usually a part of the duties devolving upon sanitary administrations, and the preliminary announcement from the committee of the American Public Health Association, indorsed by the committee of the Conference of State and Provincial Boards of Health of North America, shows how the matter has been gone about. Sanitarians and vital statisticians alone can not make this movement a complete success. The interest and help of the entire profession are necessary adjuncts. The clinician, whether practicing in city or country, whether a teacher in a medical school or a private observer, should render aid. The pathologist should consider the questions involved from his point of view. Men devoted to special branches of medicine, as pediatrics, gynecology, surgery, obstetrics, etc., should give the benefit of their experience. The aid of the various special societies should be obtained, and also, through the coopperation of the state societies, with their constituent county organizations, the friendly feeling and interest of the entire medical profession of the country should be secured for this movement to improve the accuracy and usefulness of mortality statistics. Naturally, with this object in view, we come to the American Jredical Association, and one of the purposes of the presentation of this paper is to ask the practical coöperation of the Association, by means of a special committee on vital statistics, with the corresponding committees already organized by the American Public Health Association and by the Conference of State and Provincial Boards of Health.

Many years ago a very able committee was appointed by this Association charged with the duty of "preparing a uniform plan for registration reports of births, marriages and deaths; including a nomenclature and classification of causes of death." Members of this committee were Drs. Edward Jarvis, W. L. Sutton, Wilson Jewell, Edwin M. Snow and R. W. Gibbes, and very able reports were presented to the Association at the sessions of 1858 and 1859. The intervention of the Civil War prevented the continuance of their work, and we are just beginning to be ready to-day, after over forty years, to carry out the principles of uniform and effective registration laws and uniform and comparable presentation of statistical data, especially relative to causes of death, that these pioneers of registration work so zealously advocated at that time. We now have the immense advantage of a permanently organized Census Office representing the Federal Government, and prepared to coöperate, and now effectively coöperating with the state and municipal registration offices and with the committees of those organizations that have undertaken to aid in this work. We now have the great additional advantage of a more thoroughly organized and united medical profession, and by its aid, under the auspices of the American Medical Association, these desirable reforms can be rapidly brought to accomplishment. It is time that a committee was again organized by the Association for this purpose, and I trust that your recommendation will be heartily given for this purpose.

\section{DISCUSSION.}

Dr. J. S. Fulton, Baltimore-The situation in America was never more hopeful than it is at the present time. We have a Census Bureau, which is a permanent organization. We have an energetic and (I think I may say) an enthusiastic committee working along these lines; and it certainly seems reasonable to hope that we shall, in the course of a few years, reach the individual contributors to the statistics, the physicians who make out the certificates on which the statistics are based. 
It is a great pity that our classification must be mechanical. The mathematics of the subject, as Dr. Wilbur says, very clearly show that we can only have a certain number of places for distribution of the causes of death. That necessitates the absolute loss, from certain columns of mortality, of an indefinite number of causes leading to death, and perhaps introduces inevitable error, since we who are the statisticians compiling these data are rather impressed with our own side of the question of assigning position to certificates of death. It was an excellent idea in the Census Bureau to address inquiries to a great many men in the leading specialties in medicine, asking them to express opinions or give definitions of the various titles in the international classification. I think in that way we can eliminate our own particular bias; or, if we can not eliminate it, we can minimize its error so as to make it of little practical importance.

I received one of these inquiry sheets, of which this is a printed copy, is it not, Dr. Wilbur?

DR. WILBUR-No; that is an average rating from a cudy of a number of those sheets, representing the average opinion of a certain number of statisticians and sanitarians; merely a preliminary study for the purposes of this meeting.

DR. FuLTON - I received such a sheet, asking me to give a rating to each of the titles. I went into it with care, as a man interested in the subject and as a specialist. After I was done $I$ found $m y$ mind in exactly the condition in which $D r$. Wilbur tells us the minds of so many medical men of the country are. After going over the entire list and reviewing it I found much in my own notes to criticise. Desiring to satisfy myself, I drew a second column, and put down an alternate series of ratings, and $I$ found that in all important titles - the very definite diseases-I had no inclination to change the rating at all. There were a number of titles as to which I was inclined to very slightly increase or diminish my first rating. There were a considerable number of rather indefinite titles to which, on second consideration, I gave a rating very different from that which $I$ had given at first. I was greatly interested in hearing Dr. Wilbur say that such was about the state of mind of other men.

I confess that I don't •understand how Dr. Wilbur is going to make this mathematical basis of assignment available for clerks. I am inclined to believe that he will work it out in some practical way, although at present, as I say, I don't understand it. What I do understand very clearly, however, is that this work is going to be available for a successful re vision of our classification every ten years. Such careful study year after year will enable us to take very definite and complete data to the next decennial revision. For this purpose I feel assured that the great practical utility is coming out of this part of the work; for the other I am hopeful, though I confess I don't understand it at present.

Dr. G. T. Swarts, Providence, R. I.-My feelings are precisely those stated by Dr. Fulton. When I commenced to ex press my opinion in figures in regard to the comparative valuation of these different diseases, I found myself somewhat in a quandary. After making my rating the question was whether it was satisfactory to me. I think the result will be that we will have to take the average, as was done in this acceptance of nomenclature classification. I am not satisfied with the classification at all. There are a great many subjects of im. portance left out, and a great many causes $I$ don't agree with. Nevertheless, I am willing to let my personal opinion go, so that when the statistician finds some reports from one state and some from another, he will know that they are all classified from the same standpoint.

I am willing to submit my figures to what the Census Bureau finds is a proper average. Whether it will prove satisfactory or not, seems ambiguous to me at present, but surely, in the course of ten years, we ought to get to some point where we can understand the subject. It must be, however, thoroughly threshed out in the meanwhile.

Salt and Molasses for Cancer.-Salt as a cure for cancer is announced from India in the lay press, and an Australian physician has found molasses to be a sure cure. Salt and molasses have, at least, the valuable points of cheapness and simplicity.

\section{THE PROPER PERINEAL PROSTATECTOMY INCISION.}

NICHOLAS SENN, M.D., LL.D.

Professor of Surgery Rush Medical College; Surgeon-in-Chlef St. Joseph's Hospital; Attending Surgeon Presbyterian Hospltal.

\section{CHICAgo.}

Prostatectomy is the operation which is now attracting much attention among surgeons here and abroad. The more general adoption of this operation is comparatively of recent date. The necessity of the removal of the enlarged prostate gland, the most frequent cause of urinary obstruction in men advanced in years, has been recognized for a long time, but it was not until recently that the technic of the operation has been perfected to a degree that rendered it sufficiently safe to bring it within the scope of feasible and advisable surgical procedures. The literature on this subject is growing with astonishing rapidity. Individual and collective experiences are being published in the medical press at short intervals in bringing to the notice of the profession the different operative procedures which are being devised and practiced. The question as to the most feasible route by which to attach the diseased prostate has not been definitely settled. The suprapubic method has many weighty advocates, and for a time was deemed the easiest, most efficient and safest. The perineal route has, however, been given a more extended trial, and a very large experience appears to have decided in its favor. From an anatomic standpoint the perineal operation is certainly the most rational of the two, and will undoubtedly survive the test of time. The removal of the enlarged prostate does not always meet all the indications in the case operated on. Few cases come to the surgeon in which the bladder is intact in consequence of the mechanical obstruction or infection, hence in the majority of cases it becomes necessary to establish free drainage after the removal of the prostate for the purpose of initiating a successful treatment for the coexisting complications. In making the external incision the surgeon must therefore have in view the exposure of the prostate to sight and touch as freely as can be done with safety, and to provide for free drainage of the bladder and the perineal wound. The semilunar incision of Zuckerkandl and the triangular incision of Kocher accomplish neither of these objects to the fullest extent. I have given both of them a fair test and have become familiar with their shortcomings in securing the necessary room and the difficulty encountered in establishing free and efficient drainage for the bladder and perineal wound. The triangular incision of Kocher circumscribes a long wedgeshaped flap, the apex of which is liable to slough, and the curved incision of Zuckerkandl does not procure the necessary amount of room through which the prostate, in difficult cases, can be remored with the requisite degree of precision and safety, and both incisions leave ${ }^{\mathrm{a}}$ wound difficult to drain efficiently. The median incision so much praised by some surgeons is altogether inadequate in difficult cases. Every surgeon who has had an extensive experience in perineal prostatectomy has learned that not all enlarged prostates can be removed by enucleation. There are cases in which the diseased organ must be removed by morcellement. It is a rule that surgery which it is always well to bear in mind, and thartis to operate as little as possible in the dark in importh ant anatomic localities, and this rule applies special force to perineal prostatectomy. In obese subjectand in cases of very large prostates it is often excedhin ingly difficult to bring the parts to be removed 